\title{
Improving Practical Skill in metrology and quality control by TTSM
}

\author{
Pruthviraj Chavan $^{1}$, Ajinkya Patil ${ }^{2}$, Mahesh Deshpande ${ }^{3}$ \\ ${ }^{1}$ Mechanical Engineering Department, RIT, Rajaramnagar, Islampur 415414, India. \\ ${ }^{2,3}$ Mechanical Engineering Department, RIT, Rajaramnagar, Islampur 415414, India. \\ 1 pruthviraj.chavan@ ritindia.edu \\ 2ajinkyak.patil@ ritindia.edu \\ ${ }^{3}$ mahesh.deshpande@ ritindia.edu
}

\begin{abstract}
:
Today's scenario of classroom teaching is the way where the teacher can deliver the contents and student can and understand but they are not getting practical experience because of that they are lagging in practical skill as well as filed to tackle industrial problems. For improving the practical skill of the students TTSM (Tap, Think, Solve, Make) applied to the course metrology and quality control. This paper focuses on enhancing the practical skill of students in course of metrology and quality control and get platform experience. In this pedagogy, students learn in the groups formed by push them up the method and work together to enhance practical skill, knowledge, teamwork, etc. By considering students feedback through quaternary and marks obtained through rubrics, we found that TTSM is the best tool to get practical experience.
\end{abstract}

Keywords: TTSM, platform experience, platform experience.

\section{Introduction:}

To have practical learning involvement, use of pedagogy tools supports to enhance the culture of the classroom. Each student dynamically engages in the learning practice. TTSM is a form of pedagogy which strives to involve students in the learning process.

K. Yamashita and H. Yasueda [1] explained through qualitative study under which groups formed in real and virtual seats motivate the new life of the vacant classroom as out-of-class events also conducted interviews and observed participants' use of the vacant.

L. Balan et.al.[2] implemented problem-based learning (PBL) for undergraduate students to enhance student fulfilment in a CAD modelling course by using free-choice open-ended projects and also shown that students are allowed to choose their topic for PBL have got good outcomes and extra time on it.

R. Merge et.al. [3] presented practice information concerning the practice of the Flipped classroom for the course Processer Network. Also concluded that the marks obtained in test who experienced Flipped classroom are significantly greater than the marks gained by student's use customary teaching.

L. BOT et.al. [4] describes an active culture for the learning of physical sciences and mathematics to students by
Learning by doing and showing that comparison between other well-known methods such as problem-based learning, problem-solving, etc. Learning by doing is an efficient method.

T. Hnatyshyn et.al. [5] described the teaching of Pathophysiology Using a Card Set and explained that this strategy is time and cost-efficient.

N. Hoffart et.al. [6] implemented Storyboarding as an active learning strategy that permits students to work composed to study, establish, and arrange information and understandings.

L. Wyness and F. Lynne [7] explained the result of PBL that reveals students supposed the worth of the element to lie in its object to announce them to a wider and additional nuanced understanding of sustainability and to highlight the presence of evolving substitutions to customary accounting methods.

E. Yew and K. Goh [8] suggested that PBL is an effective teaching and learning method, mainly when it is assessed for long- term data retaining and presentations.

\section{Method:}

A. Objectives:

i. To clear the concepts of gauge design.

B. What is TTSM?

TTSM is method that built shop floor culture and "prompts students to actively contribute and keep track of the steps they take in answering a problem and manufacture".

TTSM (Tap, Think, Solve, Make) consist of the following steps;

Step I: Formation of groups: The groups are formed by pushing them up method. Each group consists of two regular students, one direct second-year student, and one girl students. The purpose of this is to everyone can work together as a team i.e. teamwork and push by another group member in case of any difficulty.

Step II: Tap the Problem: Identify the need from industry and Tap the actual practical need with constraints for defining the problem.

Step III: Think over the Problem: Once the Problem is finalized think for the methodology to solve this problem.

Step IV: Solve the Problem: Solve the problem analytically as well as check with software result. 
Step V: Make a prototype or model: Arrange all the resource and manufacture.

\section{Purpose of Technique:}

- It allows viewing students' understanding level.

- Development of students analytically.

- It allows providing detailed feedback to students.

- It gives practical experience. (L. BOT et.al. 2014)

\section{Experimental Detail:}

This learning was accompanied on students completing the course, "metrology and quality control" $(\mathrm{N}=60)$ of thirdyear Mechanical Engineering at Rajarambapu Institute of Technology, Islampur. This subject having gauge design problems in the second topic. Total 15 teams have been made by pushing them up method. While creating a team rule has been followed like so this will help to solve the problem easily with great collaboration shown in fig.1. (R. Merge et.al. 2017).
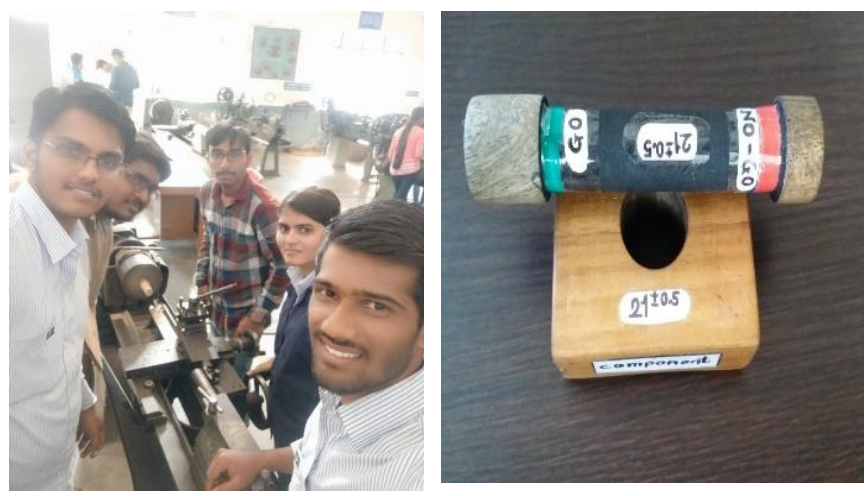

Fig.1 Applying TTSM method in class.

Each group has a time limit of 3 hours. After solving a gauge design problem of subject evaluation will be done in team-wise through rubrics shown in Table.1.

Table.1 Individual member evaluation Rubrics

\begin{tabular}{|c|c|c|c|c|}
\hline Roll No. & & & & \\
\hline Criteria's & Proficient ( $<8$ to 10) & Adequate $(<6$ to 8$)$ & Substandard $(<5$ to 6$)$ & Unacceptable ( 0 to 5 ) \\
\hline $\begin{array}{l}\text { Active } \\
\text { Participation } \\
(\mathbf{2 0 \%})\end{array}$ & $\begin{array}{l}\text { The student demonstrates an } \\
\text { accurate understanding of the } \\
\text { activity. }\end{array}$ & The student may be unprepared. & $\begin{array}{l}\text { If able to contribute, the } \\
\text { student has trouble illumination } \\
\text { key concepts. }\end{array}$ & $\begin{array}{l}\text { The student was absent } \\
\text { from or did not } \\
\text { participate. }\end{array}$ \\
\hline
\end{tabular}

Writing/

Presentation

Skills (10\%)

Inferring by

Q/A (10\%)

\section{Report}

Submission (10\%)
All content points of activity are systematically written and presented.
$61 \%-80 \%$ of content points of activity are systematically written and presented.
$51 \%-60 \%$ content points of e activity are systematically written and presented
Below $50 \%$ of content points of activity are systematically written and presented.

\section{Result Analysis:}

The lecture contains a total of 60 students for the academic year 2017-18 as well as 2018-19. In the internal assessment evaluation for Q. 2 (A) on gauge design $51.66 \%$ students below 06 marks out of 09 marks and $43.33 \%$ of students above 06 marks for academic year 2017-18 shown in Fig.2 and $32 . \%$ students below 06 marks out of 09 marks and $68 \%$ of students above 06 marks for academic year 2017-18 shown in Fig.3.

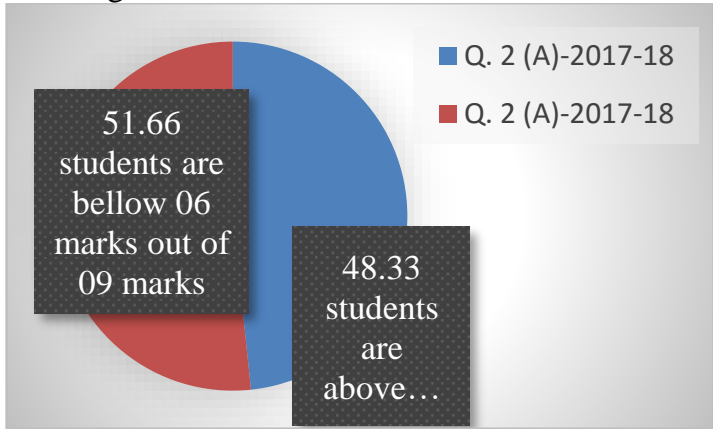

Questions are answered fairly well and/or graphs could have been done more neatly, accurately or with more complete information.
Shows Below 50\% understanding of the activity.

Student turns in activity report late or the report is so incomplete and/or so inaccurate that it is unacceptable
The student has problems with both the graphs and the answers.
Fig.2 Internal assessment result academic year 2017-18

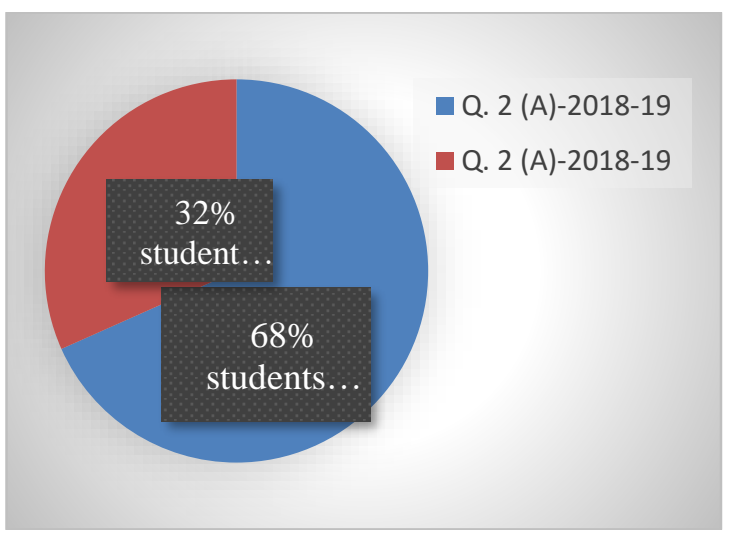

Fig.3 Internal assessment result academic year 2018-19

\section{Feedback}


After completion of a task, the feedback is given by 60 students. This feedback shows that the conceptual understanding of the students' and enthusiasm for this approach.

Table 1: Student Feedback for academic year 2019-20.

\begin{tabular}{clcccc}
\hline $\begin{array}{c}\text { Sr. } \\
\text { no. }\end{array}$ & Particular & $\begin{array}{c}\text { Poor } \\
(\mathbf{\%})\end{array}$ & $\begin{array}{c}\text { Fair } \\
(\mathbf{\%})\end{array}$ & $\begin{array}{c}\text { Good } \\
(\mathbf{\%})\end{array}$ & $\begin{array}{c}\text { Excellent } \\
(\mathbf{\%})\end{array}$ \\
\hline 1 & $\begin{array}{l}\text { Is it give you } \\
\text { practical } \\
\text { knowledge? }\end{array}$ & 5 & 12 & 18 & 25 \\
2 & $\begin{array}{l}\text { Whether it } \\
\text { helped you to } \\
\text { enhance } \\
\text { understanding } \\
\text { level? }\end{array}$ & 0 & 2 & 30 & 28 \\
3 & $\begin{array}{l}\text { Have you } \\
\text { enjoyed? }\end{array}$ & 0 & 6 & 25 & 29 \\
4 & $\begin{array}{l}\text { Would you } \\
\text { indorse similar } \\
\text { session for other } \\
\text { topics? }\end{array}$ & 5 & 12 & 20 & 23 \\
\hline
\end{tabular}

\section{Conclusion:}

This paper presented an understanding of concept by the use of TTSM for subject MQC for third-year engineering students. The Fig.2 and Fig.3 indicate that the marks obtained in Internal assessment result for the academic year 2018-19 for Q.2 (A) significantly higher than the marks obtained in Internal assessment result for the academic year 2017-18 for Q.2 (A). This means that 2018-19 students got an advanced level of taxonomy i.e., apply level compared. Whereas, 2017-18 students reached to know the level and others are at recall level only. From the feedback obtained by 2018-19 group students, it is found that students' are involved in the activity and enjoyed the TTSM classroom activity. Hence, TTSM can be the better choice to turn improving students' practical learning.

\section{Acknowledgement}

We express our sincere thanks to RIT, Islampur for providing the required facility to use a TTSM, Also, we would like to thank our beloved Director, Dean Academic, HOD of Mech., and our colleagues for their constant support which helped us to implement this practices.

\section{References}

[1] Kaori, Y. and Hidetoshi, Y. (2017) Project-based learning in out-of-class activities: flipped learning based on communities created in real and virtual spaces, International Conference on Knowledge Based and Intelligent Information and Engineering Systems, Procedia Computer Science pp 1044-1053.

[2] Lucian B., Timber, Y., and Moein M. (2019) ProblemBased Learning Strategy for CAD Software Using FreeChoice and Open -Ended group Projects, The 12th International Conference Interdisciplinary in Engineering, Procedia Manufacturing pp 339-347.

[3] Rohini, R. M., Shweta, U. B.,2 and Vaidehi, S. K. (2017) Flipped Classroom Strategy to Improve Students' Learning of Computer Communication Network: An Experience
Report, Journal of Engineering Education Transformations, 30(3), 99-102.

[4] Ludovic, B., Pol-Bernard, G., Carl-Philippe R., and Safouana, T.(2014) 'Learning by doing': a teaching method for active learning in scientific graduate education, European Journal of Engineering Education, 30(5), 105119.

[5] Tammy, H., M, N., and R, N. (2017), doi.org/10.1016/j.teln.2017.10.001.

[6] Nancy H., and Rita, D. (2016), doi.org/10.1016/j.cptl.2016.08.010.

[7] Lynne, W. and Fiona, D. (2018), doi.org/10.1016/j.jaccedu.2018.09.001.

[8] Elaine, H.J.Y. and Karen, G. (2016), doi.org/10.1016/j.hpe.2016.01.004. 